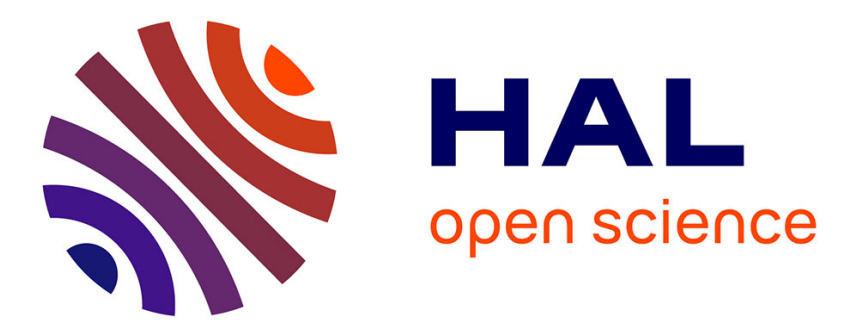

\title{
MOVPE grown periodic AlN/BAlN heterostructure with high boron content
}

\author{
Xin Li, Suresh Sundaram, Youssef El-Gmili, Frédéric Genty, Sophie
}

Bouchoüle, Gilles Patriarche, Pierre Disseix, François Reveret, Joël Leymarie, Jean-Paul Salvestrini, et al.

\section{To cite this version:}

Xin Li, Suresh Sundaram, Youssef El-Gmili, Frédéric Genty, Sophie Bouchoüle, et al.. MOVPE grown periodic AlN/BAlN heterostructure with high boron content. Journal of Crystal Growth, 2015, 414, pp.119-122. 10.1016/j.jcrysgro.2014.09.030 . hal-01212596

\section{HAL Id: hal-01212596 https://hal.science/hal-01212596}

Submitted on 13 Jan 2022

HAL is a multi-disciplinary open access archive for the deposit and dissemination of scientific research documents, whether they are published or not. The documents may come from teaching and research institutions in France or abroad, or from public or private research centers.
L'archive ouverte pluridisciplinaire HAL, est destinée au dépôt et à la diffusion de documents scientifiques de niveau recherche, publiés ou non, émanant des établissements d'enseignement et de recherche français ou étrangers, des laboratoires publics ou privés.

\section{(c) (1) $\$$}

Distributed under a Creative Commons Attribution - NonCommercial| 4.0 International 


\title{
MOVPE grown periodic AIN/BAlN heterostructure with high boron content
}

\author{
X. Li ${ }^{\text {a,b }}$, S. Sundaram ${ }^{\text {b}}$, Y. El Gmili ${ }^{\text {b }}$, F. Genty ${ }^{c}$, S. Bouchoule ${ }^{\text {d }}$, G. Patriache $^{\text {d }}$, P. Disseix ${ }^{\text {, }}$, \\ F. Réveret ${ }^{\mathrm{e}}$, J. Leymarie $^{\mathrm{e}}$, J.-P. Salvestrini ${ }^{\mathrm{b}, \mathrm{f}}$, R.D. Dupuis ${ }^{\mathrm{g}}$, P.L. Voss ${ }^{\mathrm{a}, \mathrm{b}}$, A. Ougazzaden ${ }^{\mathrm{a}, \mathrm{b}, *}$ \\ a School of Electrical and Computer Engineering, Georgia Institute of Technology, GT-Lorraine, 57070 Metz, France \\ ${ }^{\mathrm{b}}$ UMI 2958, Georgia Tech - CNRS, 57070 Metz, France \\ c Supelec, LMOPS, EA 4423, 57070 Metz, France \\ ${ }^{\mathrm{d}}$ LPN CNRS, UPR20, 91460 Marcoussis, France \\ e Institut Pascal UMR 6602 CNRS, Université Blaise Pascal, 63171 Aubière, France \\ ${ }^{\mathrm{f}}$ Université de Lorraine, LMOPS, EA 4423, $57070 \mathrm{Metz}$, France \\ ${ }^{\mathrm{g}}$ Center for Compound Semiconductors and School of Electrical and Computer Engineering, Georgia Institute of Technology, Atlanta, GA 30332, USA
}

Five-period AIN/BAIN heterostructure containing boron as high as $11 \%$ has been successfully grown by MOVPE. Good periodicity of two alternative layers has been observed by both SIMS profile and Zcontrast HAADF-STEM images. The BAIN layers demonstrate columnar polycrystalline feature. The BAIN layers exhibit an emission peak by CL and absorption edge in transmission spectra at around $260 \mathrm{~nm}$. The results enable the development of BAIGaN based multi-layered heterostructure for UV and deep UV applications.

\section{Introduction}

III-nitrides are excellent wide bandgap semiconductors which exhibit thermal stability, high thermal conductivity, mechanical strength and chemical stability. These interesting properties promote their applications for optoelectronic devices in deep UV region and also high power high frequency electronics. Besides the conventional AlGaInN system, the BAlGaN system can offer large versatility for bandgap, lattice and refractive index engineering. For instance, it is possible to decrease or eliminate lattice mismatch on SiC and AIN substrates by introducing boron [1-3]. Especially, it has been experimentally proved that a small amount of boron incorporation in AIN can introduce a strong refractive index contrast [4]. Hence the BAlGaN system has been recently proposed as a promising candidate for Distributive Bragg Reflector (DBR) applied in deep UV vertical cavity surface emitting lasers (VCSELs) [5,6]. However, challenges lie in the growth of this material. Phase separation would happen due to large bond mismatch of $\mathrm{BN}$ and other nitrides, and crystallinity was limited because of short diffusion length of boron and strong parasitic reaction in the gas phase [7-9].

Most of the studies concentrate on BAIN single layers with only $1-2 \%$ boron. High boron containing layers growth by MOVPE has

\footnotetext{
* Corresponding author. Tel.: + 333872039 23; fax: + 33387203940

E-mail address: aougazza@georgiatech-metz.fr (A. Ougazzaden).
}

not been progressed a lot, which might be because the growth is normally performed at $1000{ }^{\circ} \mathrm{C}$ or above $[2,4,10,11]$ in order to enhance $\mathrm{B}$ atoms diffusion, but at this high temperature the B-rich phase would poison the growth under high TEB/III ratio $[12,13]$. Low growth temperature can alleviate this problem and high boron incorporation can be achieved [13], but it does not facilitate growth of AlN for heterostructures or AlGaN MQWs. The fabrication of heterostructure is an important issue which needs to be further developed no matter for BAlGaN based MQWs or for DBRs.

This work reports on the growth and characterizations of 5-period AlN/BAlN heterostructure grown by metal-organic vapor phase epitaxy (MOVPE). The BAIN layers contain high boron content of $11 \%$. Crystalline features and the optical properties of this heterostructure have been studied.

\section{Experiments}

5-period AlN/BAlN layers ( $25 \mathrm{~nm} / 32 \mathrm{~nm}$ ) were grown in a MOVPE T-shape reactor [14] at 100 Torr by using hydrogen as carrier gas. The growth was performed on two types of substrates: $1 \mu \mathrm{m}$ AlN templates on sapphire and $3 \mu \mathrm{m} \mathrm{GaN}$ templates on sapphire. The AlN templates are appropriate substrates for deep UV applications while GaN templates are used as reference. The temperature was maintained at $1000{ }^{\circ} \mathrm{C}$ during the growth and TEB/III molar ratio in the vapor phase was $40 \%$ in order to have high boron incorporation. Flow- 
modulate epitaxy (FME) was applied during the growth of BAIN layers in order to enhance the migration of $\mathrm{B}$ and $\mathrm{Al}$ atoms, and also suppress parasitic reactions [9-11]. $2 \mathrm{~s}$ supply of metal-organics and $1 \mathrm{~s}$ supply of $\mathrm{NH}_{3}$ were alternatively run into the reactor without interruption $[9,10]$. The AlN layers were grown in a continuous way. A schematic of precursors feeding sequence for BAIN and AlN is presented in Fig. 1

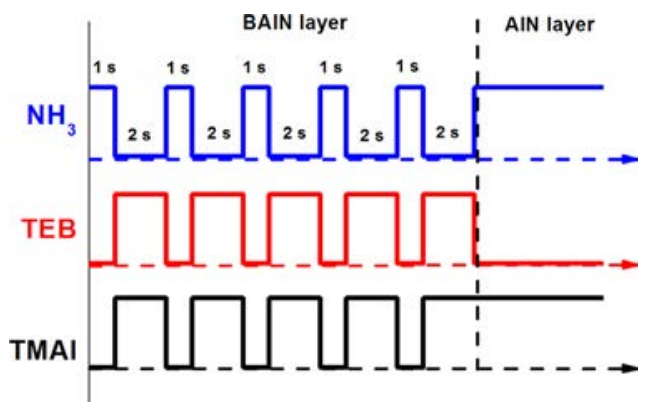

Fig. 1. Schematic of precursors feeding sequence for BAIN and AIN.
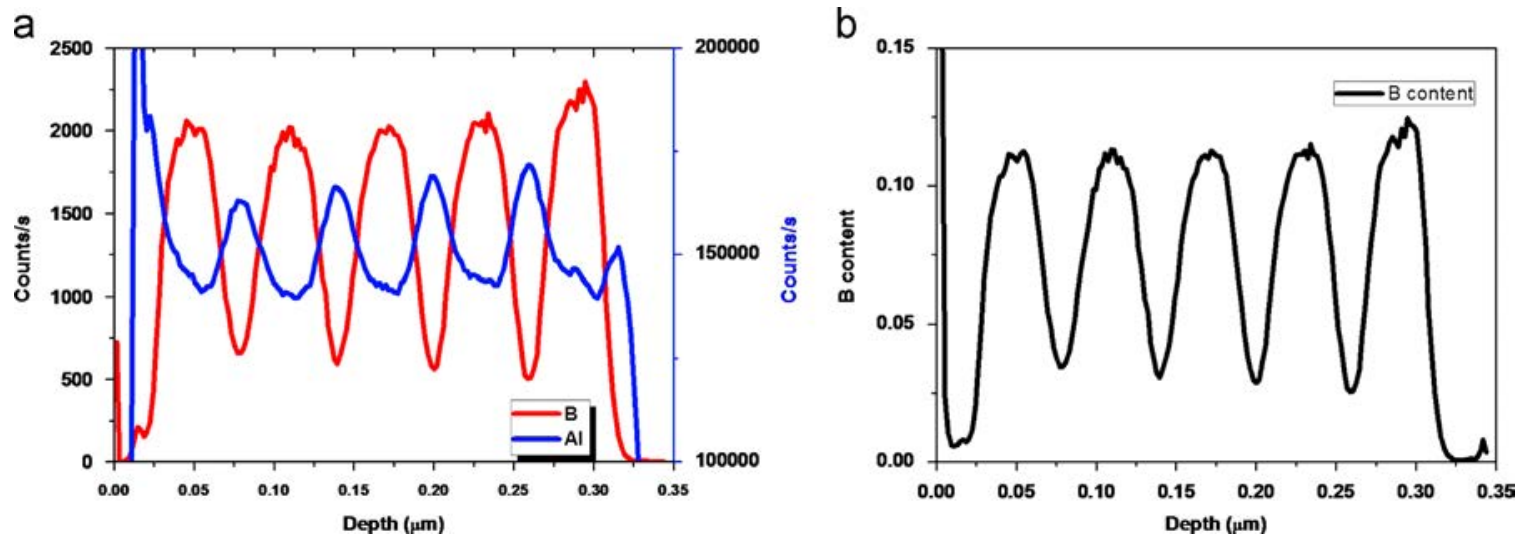

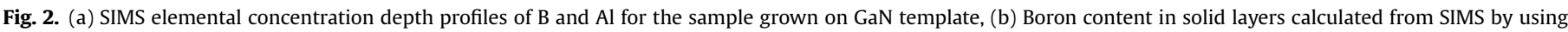
boron implanted AIN sample as reference.
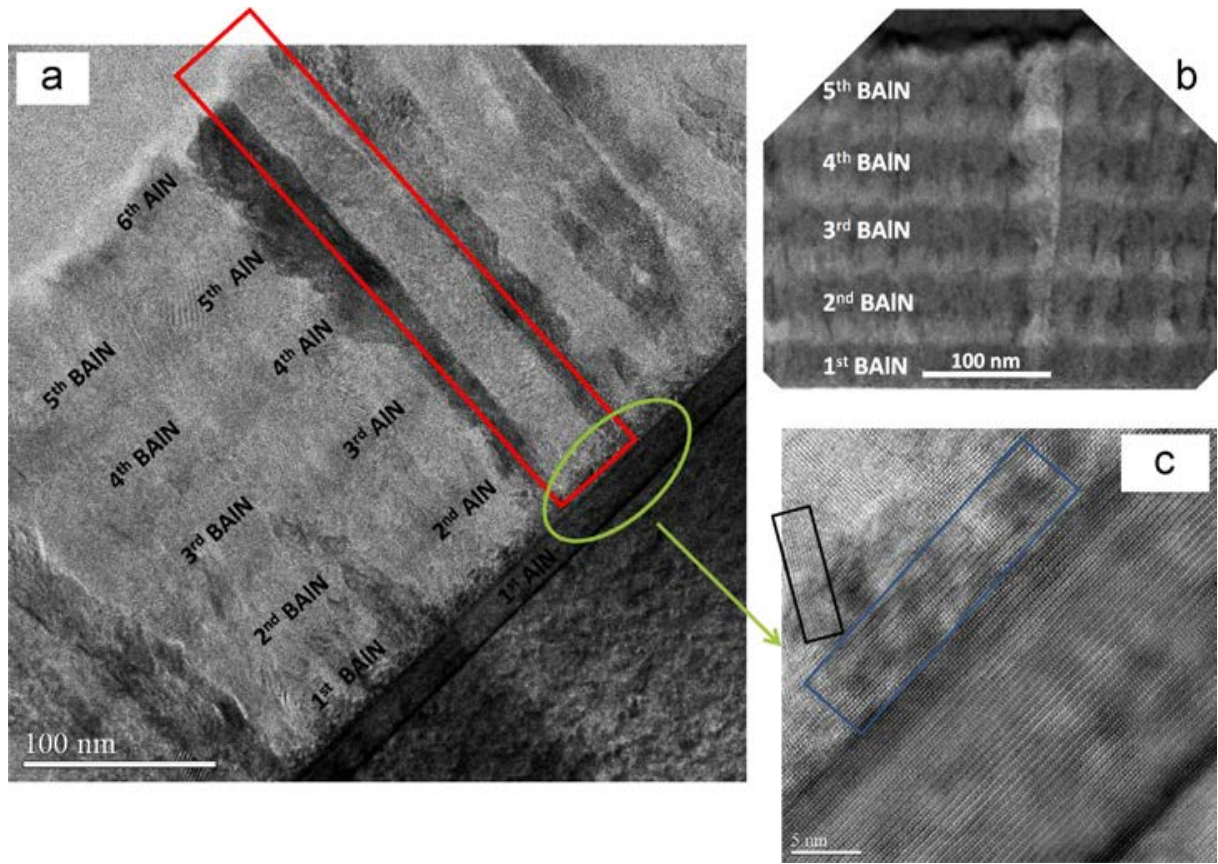

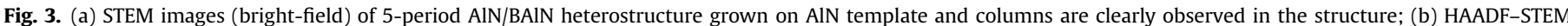
image to show better contrast of BAIN and AlN layers; and (c) high magnification of the zone where the $1^{\text {st }}$ BAIN layer starts to grow. 
intensity decreases when boron signal intensity increases during BAlN growth, which indicates that boron atoms substitute $\mathrm{Al}$ atoms on the III sites of lattice to form BAIN alloy. 5-period AIN/BAIN layers exhibit good uniformity except that the first AlN layer has lower AIN intensity which is due to some Ga contamination from the sample holder and reactor [15]. It should be pointed out that the boron signal cannot be zero when it is sputtered into AlN layer considering the SIMS detection limit when thin layers are analyzed. In order to calibrate SIMS signal for quantitative measurements of boron content in the layer, boron implanted AIN sample was used as a reference. The boron content distribution along the growth direction is presented in Fig. 2(b). Under our growth conditions, 11\% ( $\pm 0.6 \%)$ boron incorporation has been obtained.

\subsection{Crystalline features of high boron containing layers}

In order to investigate structural quality of this heterostructure and also crystalline characteristics, the cross-section STEM was

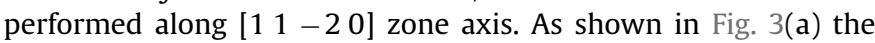
bright-field STEM image shows that the AIN/BAIN heterostructure has columnar polycrystalline features, such as the part in the rectangle box. By looking into the higher magnification image of the interface between 1st AlN and 1st BAIN in Fig. 3(c), it is clear that the 1st AlN layer is still monocrystalline. When BAIN growth starts the lattice is oriented along $c$-axis for around $5 \mathrm{~nm}$, and then a tilt as large as $60^{\circ}$ can be observed which means the structure tends to be polycrystalline and columnar growth starts. Better contrast of AIN and BAlN layers can be observed by Z-contrast HAADFSTEM images shown in Fig. 3(b), where layers with higher brightness represent AlN layers and darker layers present BAIN. The surface roughness height caused by this columnar feature is around $10-13 \mathrm{~nm}$ from STEM images.

The polycrystalline feature has been confirmed by HR-XRD results. In $2 \theta-\omega$ scans shown in Fig. 4 , a peak related to AIN $\left(\begin{array}{llll}0 & 0 & 0 & 2\end{array}\right)$ is located at $36.02^{\circ}$. Another peak at $37.98^{\circ}$ should correspond to AlN $(1-101)$. Combining with STEM results, it can be explained that the first AIN layer was monocrystalline along c-axis. After the BAIN starts to grow, the structure becomes polycrystalline and epitaxial AIN layers grown afterwards also have lattice tilt so that X-ray diffraction signal from other facets arises. BAIN XRD peak was absent due to its polycrystalline feature especially with high boron incorporation.

This AlN/BAlN heterostructure has total thickness of $310 \mathrm{~nm}$. The morphology is examined by AFM shown in Fig. 5. The surface was covered by columnar crystallites, confirming the STEM observations. The AFM scan area is $5 \mu \mathrm{m} \times 5 \mu \mathrm{m}$ square. The structure has root-mean-square (RMS) of $3.3 \mathrm{~nm}$. The average height of these columnar crystallites is around $10 \mathrm{~nm}$ which is in a good agreement with estimations from cross-section STEM images.

The polycrystalline feature was caused by the short diffusion length of boron atoms, which would challenge the applications of this material. From STEM image we observed that the monocrystalline critical thickness for BAlN with $11 \%$ boron is around $5 \mathrm{~nm}$, above which the polycrystalline growth occurs. Meanwhile, the monocrystalline critical thickness is around $500 \mathrm{~nm}$ for BAlN of $2 \%$ boron as reported in the literature [10]. The larger the boron incorporated, the smaller the monocrystalline thickness of BAIN. Therefore, for different applications, a compromise can be achieved between thickness and boron composition. For example, for deep UV-DBRs, boron incorporation no more than $5 \%$ is enough to achieve high refractive index contrast $[4,5]$. Hence the boron content can be decreased to maintain BAIN layers (30-40 nm) monocrystalline. For ultra-thin layers such as MQWs or strain engineering superlattices, high boron incorporation can be used allowing a

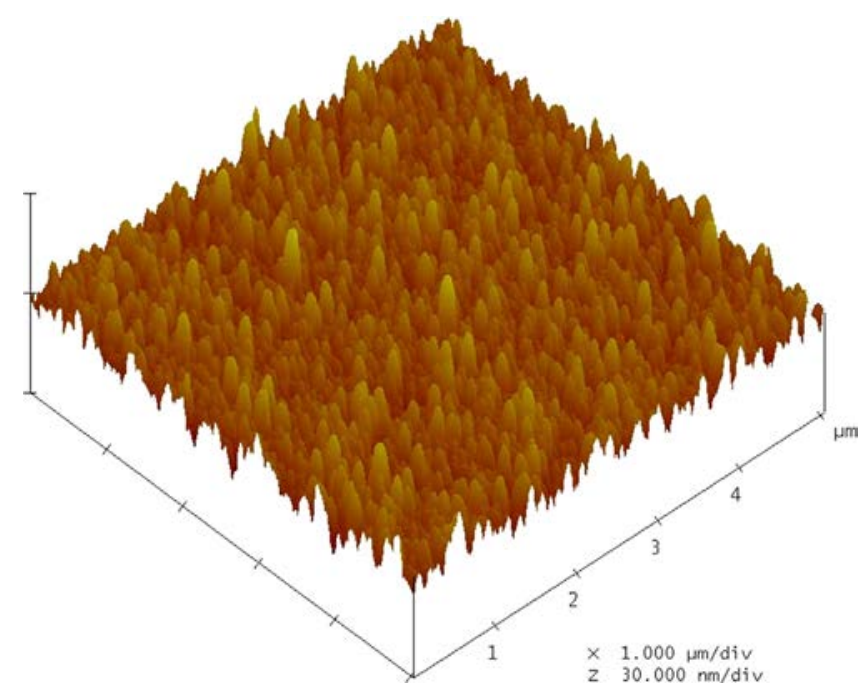

Fig. 5. Atomic force microscopy (AFM) image of 5-period AIN/BAIN heterostructure (310 $\mathrm{nm}$ for total thickness).
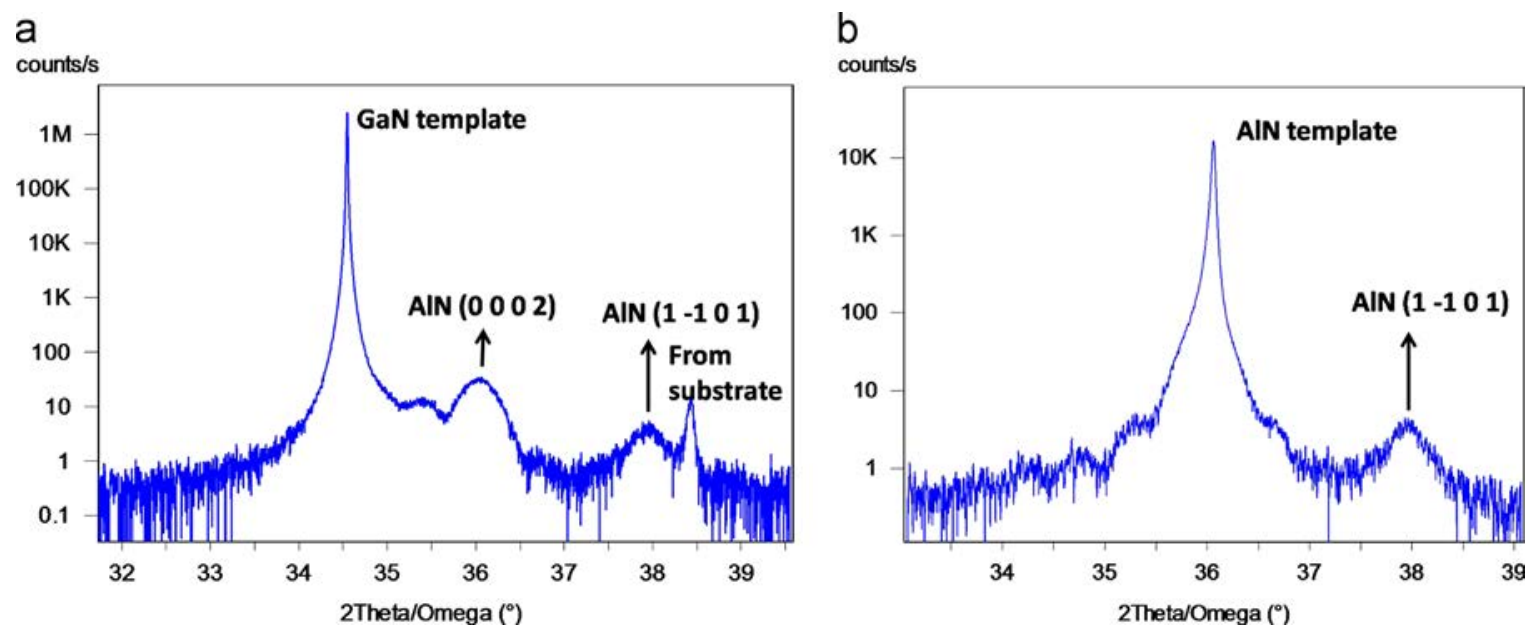

Fig. 4. h-XRD $2 \theta-\omega$ scans of 5-period AIN/BAlN heterostructure grown on (a) GaN template and (b) AlN template. 


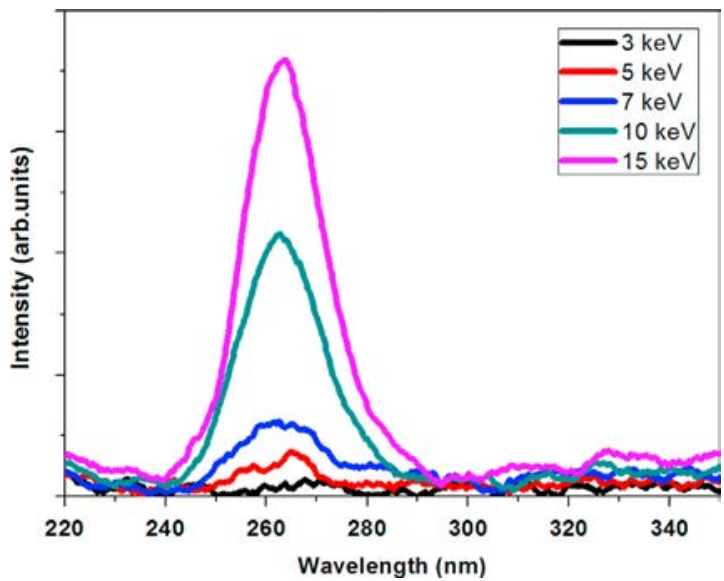

Fig. 6. Cathodoluminescence spectra at $77 \mathrm{~K}$ of 5-period AIN/BAIN heterostructure grown on AlN template.

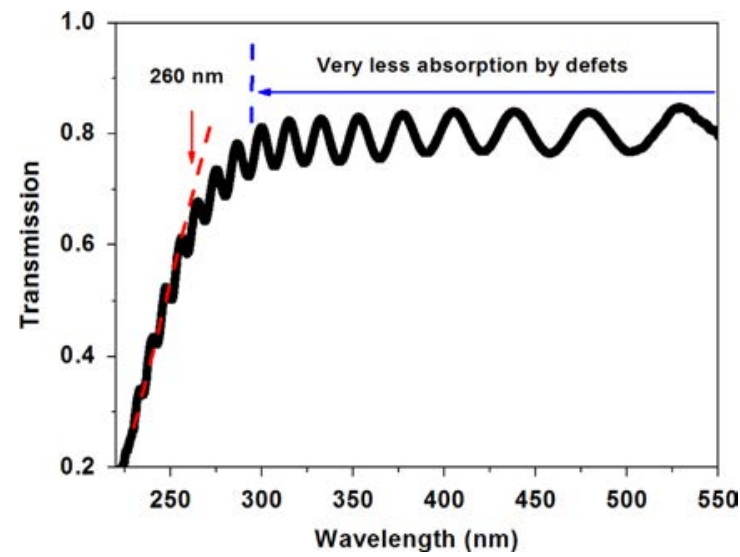

Fig. 7. Transmission spectrum at room temperature of 5-period AlN/BAIN heterostructure grown on AIN template.

large design freedom and it can still be kept as monocrystalline for its thin thickness (below $10 \mathrm{~nm}$ ).

\subsection{Optical properties for deep UV wavelengths}

In order to study optical properties of this heterostructure containing high boron, cathodoluminescence $(\mathrm{CL})$ and transmission spectra have been obtained for the sample grown on AlN template. As shown in Fig. 6, a well-defined emission peak at $262 \mathrm{~nm}$ emerges when the excitation power is above $7 \mathrm{keV}$. Meanwhile, as shown in Fig. 7, the optical absorption occurred at $260 \mathrm{~nm}$ which agrees well with CL results. For the wavelengths longer than $290 \mathrm{~nm}$, the oscillation level of transmission fraction remains constant, which implies that there is very little absorption by defects in this region. The results obtained exhibit potentials to apply this material and structure for UV and deep UV devices.

It is noted that $\mathrm{CL}$ emission peak of AlN has not been detected due to limitation of our detector below $210 \mathrm{~nm}$. In addition, since emission wavelength of BAlN is at $260 \mathrm{~nm}$, the emission around $200 \mathrm{~nm}$ of AlN would be absorbed by the BAlN layers. As shown in Fig. 7 of transmission curve, there is a transmission drop at $260 \mathrm{~nm}$, and below $260 \mathrm{~nm}$, there is a large absorption.

Until now, few results have been reported on optical properties of BAIN material, especially for high boron containing layers. Theoretical calculations show that BAIN has strong bowing parameter $(5.45 \mathrm{eV})[16]$, and for BGaN material the value of $9.2 \mathrm{eV}$ has been experimentally obtained [17]. Based on this prediction, our BAIN layers should give an emission at around $225 \mathrm{~nm}$. Here we observed a significant redshift of wavelength which might be due to high concentration of carbon impurities incorporated from TEB precursors (carbon density about $2 \times 10^{19} \mathrm{~cm}^{-3}$ by SIMS). Since BAIN material is not as well studied as other III-nitrides, it still requires more experimental investigations for its optical properties.

\section{Conclusion}

5-period AlN/BAlN heterostructure with $11 \%$ boron has been grown by MOVPE. Good periodicity of two different layers has been achieved. The structure shows an emission peak and absorption edge at $260 \mathrm{~nm}$ which would be promising for UV-DBRs and deep UV devices. Although it still needs more efforts to improve crystalline quality and surface roughness caused by columnar growth of BAIN the studies in this work give better understanding of high boron containing layers and heterostructure growth, which would be helpful for the development of BAlGaN applications.

\section{Acknowledgment}

This work was supported by French ANR (Agence Nationale de la Recherche) in the framework of VESUVE project (ANR-11-BS03-0012).

\section{References}

[1] M.Haruyama, T. Shirai, H. Kurimoto, H. Kawanishi, in: Proceedings of the International Symposium on Blue Laser and Light Emitting Diode, Tokyo, 1996 p. 106.

[2] A.Y. Polyakov, M. Shin, W. Qian, M. Skowronski, D.W. Greve, R.G. Wilson, Growth of AlBN solid solutions by organometallic vapor-phase epitaxy, J. Appl. Phys. 81 (1997) 1715.

[3] A. Nakajima, Y. Furukawa, H. Yokoya, H. Yonezu, Growth of $\mathrm{B}_{x} \mathrm{Al}_{1-x} \mathrm{~N}$ layers using decaborane on SiC substrates, J. Cryst. Growth. 278 (2005) 437.

[4] S. Watanabe, T. Takano, K. Jinen, J. Yamamoto, H. Kawanishi, Refractive indices of $\mathrm{B}_{x} \mathrm{Al}_{1-x} \mathrm{~N}(x=0-0.012)$ and $\mathrm{B}_{y} \mathrm{Ga}_{1-y} \mathrm{~N}(y=0-0.023)$ epitaxial layers in ultraviolet region, Physica Status Solidi C 0 (2003) 2691.

[5] M. Abid, T. Moudakir, G. Orsal, S. Gautier, A. En Naciri, Z. Djebbour, et al. Distributed Bragg reflectors based on diluted boron-based BAlN alloys for deep ultraviolet optoelectronic applications, Appl. Phys. Lett. 100 (2012) 051101.

[6] M. Abid, T. Moudakir, Z. Djebbour, G. Orsal, S. Gautier, A. En Naciri, et al., Blueviolet boron-based Distributed Bragg Reflectors for VCSEL application, J. Cryst. Growth. 315 (2011) 283.

[7] J.H. Edgar, D.T. Smith, C.R. Eddy, C.A. Carosella, B.D. Sartwell, c-Boronaluminum nitride alloys prepared by ion-beam assisted deposition, Thin Solid Films. 298 (1997) 33.

[8] L. Liljeholm, J. Olsson, Electrical characterization of wurtzite $(\mathrm{Al}, \mathrm{B}) \mathrm{N}$ thin films, Vacuum 86 (2011) 466.

[9] T. Akasaka, Y. Kobayashi, T. Makimoto, Nonpolar AlBN (1120) and (1100) films grown on SiC substrates, Appl. Phys. Lett. 91 (2007) 041914.

[10] T. Akasaka, T. Makimoto, Flow-rate modulation epitaxy of wurtzite AlBN, Appl Phys. Lett. 88 (2006) 041902.

[11] H. Kawanishi, T. Honda, Fabrications of BAlGaInN multi-layer or quantum well structure for blue to UV light emitter and its applications to optical devices, Photonics Based on Wavelength Integration and Manipulation 2 (2005) 19.

[12] A.Y. Polyakov, M. Shin, M. Skowronski, D.W. Greve, R.G. Wilson, A.V. Govorkov, et al., Growth of GaBN ternary solutions by organometallic vapor phase epitaxy, J. Electron. Mater. 26 (1997) 237.

[13] X. Li, S. Sundaram, Y. El Gmili, T. Moudakir, F. Genty, S. Bouchoule, et al., BAIN thin layers for deep UV applications, in: Proceedings of the E-MRS Spring Meeting, 2014.

[14] S. Gautier, C. Sartel, S. Ould-Saad, J. Martin, A. Sirenko, A. Ougazzaden, GaN materials growth by MOVPE in a new-design reactor using DMHy and $\mathrm{NH}_{3}$, J. Cryst. Growth. 298 (2007) 428.

[15] J. Kim, Z. Lochner, M.-H. Ji, S. Choi, H.J. Kim, J.S. Kim, et al., Origins of unintentional incorporation of gallium in InAlN layers during epitaxial growth, part II: effects of underlying layers and growth chamber conditions, J. Cryst. Growth. 388 (2014) 143.

[16] S. Azzi, A. Zaoui, M. Ferhat, On the importance of the band gap bowing in Boron-based III-V ternary alloys, Solid State Commun. 144 (2007) 245.

[17] A. Ougazzaden, S. Gautier, T. Moudakir, Z. Djebbour, Z. Lochner, S. Choi, et al. Bandgap bowing in BGaN thin films, Appl. Phys. Lett. 93 (2008) 083118. 